\title{
INVENTARISASI JENIS-JENIS TUMBUHAN DAN KESESUAIAN LAHAN UNTUK KONSERVASI DAERAH TANGKAPAN SUMBER MATA AIR 'WETIHU' DESA BAUDAOK KECAMATAN TASIFETO TIMUR - BELU
}

\author{
Wahyu Widiyono \\ Peneliti Madya-IVC, Puslit Biologi LIPI \\ JL. It. H. Juanda 18 Bogor \\ wahyu_widiyono@yahoo.com
}

\begin{abstract}
Water deficit is the main constraint to develop agriculture in the border area, Belu District, East Nusa Tenggara Province. However, some wells in this area need to be conserved by planting of selected species at the watershed area in order the water available continually during a year. To understand the native and crop species that suitable to plant conservation the survey at the watershed of 'Wetihu', Baudaok-Belu was conducted in 2008. Aim of survey was to inventory the species and to understand land suitability based on its soil fertility and microclimate condition. Watershed landscape of 'Wetihu' in Baudaok Village, Belu District are characterized by rolling to hilly altitude, coral reef and limestone of soil material and the low soil fertility. Micro-climate in this area resulted the marginal land watershed and due to this problem the crop almost can not be planted by the local people. The observation by the distance of $1.5 \mathrm{~km}$ from 'Baudaok' well to the southern was found 39 wild and crop species. Some species which are able to adapt to the drought ecosystem and has potential to plant as economic crops are recommended to be selected, i.e.: the main food (Zea mays, Cajanus cajan), fruits (Musa paradisiaca, Mangifera indica), cattle feeding (Leucaene leucocephala, Sesbania grandiflora), handmade material (Bambusa sp.), fire wood, wind break trees and cover crops (Zizyphus mauritiana, Alstonia scholaris, Erythrina orientalis, Gmelina arborea, Schleichera oleosa), perfume oil producer (Santalum album).
\end{abstract}

Key Words: native species, crops, watershed, conservation, Belu, East Nusa Tenggara Province

\section{PENDAHULUAN}

Di laporkan oleh Badan Pemberdayaan masyarakat Desa (BPMD) di Kabupaten Belu terdapat 276 sumber mata air, salah satu diantaranya ialah sumber mata air Wetihu, Desa Baudaok, Kecamatan Tasifeto Timur.

Dari penelitian ${ }^{1}$ sumber mata air Wetihu memiliki debit air 100 liter/detik yang amat berpotensi untuk konsumsi rumah tangga maupun sumber energi listrik mikrohidro.
Berdasarkan penelitian geolistrik, diketahui wilayah yang diduga sebagai lintasan air bawah tanah sebagai pemasok sumber air Wetihu, yakni sejauh lebih kurang 1,5 km dari posisi sumber air ke arah selatan.

Daerah tangkapan yang diduga sebagai lintasan air bawah tanah sebagai pemasok sumber mata air Wetihu tersebut perlu dikonservasi menggunakan berbagai jenis 
tanaman agar ketersediaan air terpelihara sepanjang tahun. Hal ini karena, tumbuhan telah lama dikenal memiliki peranan terhadap konservasi sumber air dan tanah, melalui bagian-bagian tumbuhan seperti: tajuk tumbuhan berperanan menahan laju butiran hujan agar tidak jatuh langsung ke permukaan tanah; batang pohon menahan aliran air hujan melalui aliran batang; dan perakaran tumbuhan meningkatkan infiltrasi tanah sehingga meningkatkan daya simpan air di dalam tanah. Tanah yang bervegetasi akan mempertahankan kestabilan debit air sepanjang tahun, sebaliknya pada tanah yang gersang akan terjadi perbedaan debit yang besar antara musim hujan dan musim kemarau. Keberadaan hutan memberikan pengaruh positif dan negatif terhadap tata air dan tanah. Dinyatakan oleh ${ }^{2}$ bahwa (1) hutan berpengaruh positif, karena akan meningkatkan hasil air DAS, dan sebaliknya penebangan hutan akan menurunkan hasil air DAS; (2) hutan berpengaruh negatif, yakni mengkonsumsi air dalam jumlah besar sehingga adanya hutan akan menurunkan hasil air.

Mengingat terjadi ketidakseimbangan antara luas lahan subur dan jenis tanaman yang akan diusahakan maka perlu dilakukan evaluasi lahan (land evaluation) sebelum melakukan kegiatan konservasi secara vegetatif melalui berbagai jenis tanaman. Evaluasi lahan diperlukan untuk mencapai kesesuaian lahan (land suitability) pada kegiatan konservasi vegetatif. Menurut ${ }^{3)}$ kesesuaian lahan ialah kecocokan lahan untuk tanaman pertanian baik tanaman semusim maupun tanaman tahunan. Kesesuaian lahan ditentukan berdasarkan (1) persyaratabnn tumbuh tanaman (ekologis); (2) tingkat kesuburan tanah dan (3) tingkat bahaya erosi (konservasi tanah dan air).

Untuk penghijauan daerah tangkapan air diperlukan jenis-jenis tanaman yang sesuai dengan kondisi tanah dan iklim setempat. Tumbuhan dan tanaman budi daya di suatu tempat perlu mendapat prioritas pengembangannya, mengingat tumbuhan dan tanaman tersebut telah terbukti memiliki daya adaptasi yang baik. Menurut ${ }^{4}$ ) berdasarkan survey ekologi pada berbagai jenis tanaman di Pulau Timor dan Sumba, dianjurkan menggunakan berbagai jenis tanaman tersebut untuk penghijauan sesuai dengan habitat aslinya.

Sebagai dasar kegiatan konservasi daerah tangkapan berdasarkan kesesuaian lahan, telah dilakukan inventarisasi jenisjenis tumbuhan dan pengambilan sampel tanah pada beberapa titik sepanjang lintasan tersebut. Dari pengamatan tersebut diharapkan dapat diketahui jenisjenis tumbuhan yang saat ini tumbuh dan jenis-jenis tumbuhan lain yang sebaiknya dikembangkan.

Tujuan penelitian ialah (1) inventarisasi dan identifikasi jenis-jenis tumbuhan dan tanaman budidaya di daerah tangkapan sumber air, dan (2) mengetahui tingkat kesesuaian lahan jenis-jenis tanaman tersebut untuk konservasi daerah tangkapan air sesuai dengan kondisi tanah dan iklim setempat.

\section{BAHAN DAN METODA}

Telah dilakukan inventarisasi dan identifikasi jenis-jenis tumbuhan, dan pengambilan sampel tanah pada 4 titik yang diduga sebagai lintasan daerah tangkapan air Wetehu, Desa Baudaok, Kecamatan Tasifeto Timur, Kabupaten Belu (Tabel 1). Wilayah pemukiman Desa Baudaok berada pada ketinggian $584 \mathrm{~m}$ di atas permukaan laut.

Pada tiap-tiap titik pengamatan, dibuat 2 (dua) plot ke arah Timur dan Barat, masingmasing seluas $20 \times 50 \mathrm{~m}^{2}$. Jenis-jenis tumbuhan diamati secara langsung, dan untuk jenis-jenis yang belum dikenali diambil sampel herbariumnya untuk diidentifikasi di laboratorium.

Selain jenis-jenis tumbuhan di dalam plot, pengamatan juga dilakukan terhadap jenis-jenis tumbuhan yang berada di sekitar titik pengamatan. Pada masing-masing 
Tabel 1. Titik koordinat lokasi pengambilan sampel tanah dan inventarisasi tumbuhan

\begin{tabular}{|l|l|l|}
\hline Plot & Lintang Selatan & \multicolumn{1}{c|}{ Bujur Timur } \\
\hline 1 & 09.03 .37 .3 & 125.03 .40 .1 \\
\hline 2 & 10.03 .37 .3 & 125.03 .85 .9 \\
\hline 3 & 11.03 .37 .3 & 125.03 .99 .7 \\
\hline 4 & 12.03 .37 .3 & 125.03 .72 .0 \\
\hline
\end{tabular}

petak diambil sampel tanahnya, kemudian dicampur untuk mewakili satu lokasi titik pengamatan.

Untuk menduga tingkat kesesuaian lahan terhadap suatu jenis maka jenis-jenis tanaman yang telah teridentifikasi dipadukan (cross check) dengan persyaratan tumbuh ideal tanaman tersebut berdasarkan: (1) data analisis tanah, (2) data iklim, dan (3) tinggi tempat dari permukaan laut ${ }^{3)}$. Evaluasi lahan yang dilakukan dalam penelitian ini ialah evaluasi lahan pada tingkat tinjau (umum) dengan prosedur mencocokkan kualitas/karakteristik lahan dengan kriteria kelas kesesuaian lahan untuk tanaman yang akan dikembangkan. Prosedur evaluasi yang lain ialah semi detail dan detil dengan meningkatkan parameter pengukuran secara kuantitatif dan kualitatif.

\section{HASIL DAN PEMBAHASAN}

\subsection{Lanskap dan vegetasi daera tangkapan sumber air Wetihu-Belu}

Landskap daerah tangkapan sumber air Wetihu, dicirikan oleh areal berbukit-bulit batu karang bertanah kapur warna putih yang diselang-seling dengan tanah berwarna merah. Luasan lahan berbatu kapur tampak lebih dominan dibandingkan luasan tanah merah. Tanah berbatu kapur juga kurang subur dibandingkan tanah merah. Mengingat kondisi lahan tersebut jenis-jenis tumbuhan di areal tanah berbatu kapur adalah tumbuhan tahunan, sedangkan pada tanah merah merupakan tanaman budi daya semusim (jagung dan palawija) yang ditanam pada musim hujan. Jenis dan manfaat tanaman di Desa Baudaok berdasarkan hasil survey, disampaikan pada Lampiran 1.

Pada Titik pengamatan 1, yang berlokasi di dekat pekarangan rumah penduduk terdapat jenis-jenis tanaman budidaya yaitu akasia, cendana, lamtoro, johar, asam, turi, kusambi dan, jambu biji, dan kelapa; dan tumbuhan liar yaitu pole, beringin, kukbai, kom, lantana camara, bunga kuning. Selain itu di luar plot pengamatan dijumpai mengkudu, litsusu, jambu mente, mangga, sirsak, dadap, nangka, pepaya, pisang, kelapa. Pada lahan tanah merah, berada di daerah cekungan yang diduga persis sebagai daerah tangkapan air terlihat bekas tanaman budidaya semusim (jagung dan palawija). Antara titik pengamatan 1 dan titik 2, berjarak lebih kurang 250 m dari titik 1 merupakan puncak bukit berbatu kapur, ditumbuhi oleh pohon mangga liar.

Pada Titik pengamatan 2, yang lokasinya berdekatan dengan pekarangan penduduk, terdapat jenis tumbuhan lebih sedikit dari pada lokasi Titik 1, yaitu pohon jati yang ditanam sebagai batas lahan pada tanah berbatu kapur. Tanaman budidaya lain ialah mangga, kelapa dan cendana; dan tumbuhan liar ialah nikis, kom, dadap, pole, kusambi dan kedodondong hutan, cycas. Pada lahan bertanah merah terlihat sisa tanaman budidaya yaitu jagung, lamtoro, an cajanus cajan. Di luar petak pengamatan terlihat tumbuhan mangga, kemiri, annona, kapok dan sirih. Pada lokasi tersebut tumbuh pohon mangga besar yang memiliki lingkar batang mencapai $410 \mathrm{~cm}$.

Pada Titik pengamatan 3 , yang berlokasi jauh dari perkampungan penduduk terdapat jenis-jenis tumbuhan pole, bunga kuning (sufmolok), belukar tumbuhan berbunga putih (sufmuti), mangga, bambu andong, bambu hiris, jati, gmelina, pakis, jarak rambutan, cendana, mindi. Tanah merah berbatu karang lapisan tanah atas (solum) dangkal.

Pada Titik pengamatan 4, yang berlokasi jauh dari perkampungan terdapat tumbuhan belukar bunga putih, seperti johar, bunga kuning, cendana, pole, kemiri. 
Pada Titik pengamatan 1,2,3,4 yang diduga merupakan 'lintasan jalur air' berada pada lokasi di luar perkampungan penduduk dan berada pada dataran lebih tinggi dari pada titik sumber air. Areal tersebut umumnya lebih gersang dibandingkan dengan areal perkampungan penduduk. Areal perkampungan penduduk yang berdekatan dengan sumber air ditanami berbagai jenis tanaman budi daya yaitu sirih, pinang, pisang.

Jenis-jenis tanaman yang terdapat di daerah tangkapan air Wetihu merupakan jenis-jenis tumbuhan yang umum di daratan Pulau Timor seperti di daerah tangkapan air 'embung' Oemasi, Oelomin dan OeltuaKupang 5), di 'embung' Bu'at TTS, 'embung' Sasi-TTU6), 'embung' Leosama-Belu') dan 'embung' Sirani-Haliwen-Belu.

\section{2. Tingkat kesuburan tanah}

Dari analisis tanah pada 4 titik pengambilan sampel di Desa Baudaok dengan kriteria $^{8)}$ terlihat tanah memiliki tekstur lempung berdebu (silt loam) dan lempung (silt), dengan kedalaman efektif dangkal (kurang dari $25 \mathrm{~cm}$ ), $\mathrm{pH}$ netral $(7,1-7,6)$, kapasitas tukar kation tinggi $(35,66-40,73)$, kejenuhan basa sangat tinggi (mencapai 100\%), dengan nisbah antara C/N rendah (Tabel 2).

Tabel 2. Sifat Fisik dan Kimiawi Tanah Daerah Tangkapan Air

\begin{tabular}{|l|l|l|l|l|l|}
\hline Plot & Tekstur & $\begin{array}{l}\text { Kedalaman } \\
\text { efektif }\end{array}$ & $\mathbf{p H}$ & $\mathbf{K T K}$ & $\mathbf{K B}$ \\
\hline 1 & $\begin{array}{l}\text { lempung } \\
\text { berdebu }\end{array}$ & dangkal & netral & tinggi & $\begin{array}{l}\text { sangat } \\
\text { tinggi }\end{array}$ \\
\hline 2 & $\begin{array}{l}\text { lempung } \\
\text { berdebu }\end{array}$ & dangkal & netral & tinggi & $\begin{array}{l}\text { sangat } \\
\text { tinggi }\end{array}$ \\
\hline 3 & $\begin{array}{l}\text { lempung } \\
\text { berdebu }\end{array}$ & dangkal & netral & tinggi & $\begin{array}{l}\text { sangat } \\
\text { tinggi }\end{array}$ \\
\hline 4 & debu & dangkal & netral & tinggi & $\begin{array}{l}\text { sangat } \\
\text { tinggi }\end{array}$ \\
\hline
\end{tabular}

Keterangan: $\quad \mathrm{KTK}=$ kapasitas tukar kation. $\mathrm{KB}=$ kejenuhan basa.

Jenis tanah di wilayah Desa Baudaok adalah tanah lempung berdebu dan debu yang memiliki kandungan debu dan liat yang tinggi, dan kandungan pasir hanya 0-1\%. Sifat tanah tersebut bersifat kedap air, memiliki infiltrasi rendah dan sebaliknya laju aliran permukaan tinggi. Sebagai tanah berbatu karang dan kapur memiliki kedalaman efektif rendah, kurang dari 25 $\mathrm{cm}$. Derajat kemasaman tanah tergolong netral dengan $\mathrm{pH}$ 7,1 hingga 7,6. Kapasitas tukar kation (KTK) tinggi didominasi oleh kandungan kalsium (Ca) dengan kandungan Magnesium (Mg), Kalium (K) dan Natrium $(\mathrm{Na})$ rendah. Nisbah $\mathrm{C} / \mathrm{N}$ rendah disebabkan oleh kandungan karbon (C) sedang hingga tinggi dan kandungan nitrogen $(\mathrm{N})$ sedang.

Tekstur tanah lempung berdebu dikatagorikan sebagai bertekstur sedang8). Tekstur tanah berkaitan dengan plastisitas, permeabilitas, kekerasan, kesuburan dan prduktivitas tanah ${ }^{9}$. Tekstur tanah sedang memiliki tingkat kesesuaian lahan S (sesuai) untuk budidaya jagung, mangga, pisang, kelapa, jati, mahoni, lamtoro dan akasia ${ }^{3)}$.

Nisbah $\mathrm{C} / \mathrm{N}$ rendah berarti proses dekomposisi bahan organik berlangsung baik atau telah terjadi pelepasan nitrogen ke dalam tanah. Nitrogen merupakan salah satu unsur makro yang diperlukan utnuk pertumbuhan tanaman.

Derajad kemasaman $(\mathrm{pH})$ yang tinggi atau $\mathrm{pH}$ netral pada tanah karang berbatu kapur ini memiliki tingkat kesesuaian lahan berbeda untuk berbagai jenis tanaman. Masing-masing tanaman menghendaki kesesuaian derajad keasaman tanah, yakni jagung $(5,5-7,5)$, pisang $(4,5-7,5)$, jati, mahoni $(5-7,5)$ dan lamtoro $(6-8,5)$.

Kapasitas Tukar Kation (KTK) tinggi artinya tanah di daerah ini memerlukan pemupukan dalam jumlah yang tinggi agar dapat tersedia bagi tanaman. Bila diberikan dalam jumlah sedikit maka akan kurang tersedia bagi tanaman, karena lebih banyak yang terjerab. Berbagai jenis tanaman umumnya menghendaki KTK rendah-sedang, misalnya untuk tanaman jagung, mangga, pisang dan kelapa. Tetapi untuk tanaman jati, lamtoro, mahoni dan akasia tidak memerlukan persyaratan KTK yang rumit. 
Kejenuhan Basa (KB) sangat tinggi artinya hampir seluruh bagian dari kapasitas tukar kation (KTK) ditempati oleh kation basa ( $\mathrm{Ca}, \mathrm{Mg}, \mathrm{K}$ dan $\mathrm{Na}$ ). Kejenuhan basa dipengaruhi oleh iklim (curah hujan) dan $\mathrm{pH}$ tanah. Pada wilayah beriklim kering KB cenderung besar, demikian pula pada tanah ber $\mathrm{pH}$ tinggi, nilai KB lebih besar.

Tingkat kesuburan tanah yang tercermin dari sifat fisik dan kimiawi tanah tersebut akan menentukan kesesuaian lahan baik tumbuhan alami maupun jenis tanaman budidaya.

\subsection{Kondisi iklim}

Sifat fisik dan kimiawi tanah tersebut dibentuk oleh faktor iklim di daerah setempat yang memiliki rata-rata curah hujan 2000$2500 \mathrm{~mm} /$ tahun. Curah hujan ini relatif tinggi bila dibandingkan dengan rata-rata curah hujan di NTT pada umumnya hanya 1000 $\mathrm{mm}$ /tahun, bahkan pada beberapa wilayah seperti di Pulau Alor memiliki curah hujan yang sangat rendah hingga mencapai kurang dari 1000 mm/tahun. Curah hujan yang tinggi di wilayah Desa Baudaok tersebut tidak secara langsung memberikan kontribusi pada peningkatan kesuburan tanah, karena bahan induk tanah berupa batu karang dan marl (batu gamping). Diduga kontribusi lebih besar pada tersedianya cadangan air tanah, berupa sumber-sumber mata air, akibat infiltrasi ke lapisan kedap air di bawah permukaan tanah (water table).

Kondisi iklim mikro di sekitar sumber mata air Baudaok, Kecamatan Tasifeto Timur seperti kondisi iklim di Kabupaten Belu pada umumnya (Gbr. 1). Digunakan kriteria bulan basah memiliki curah hujan (lebih besar dari $100 \mathrm{~mm}$ ) dan bulan kering memiliki curah hujan (kurang dari 100 mm) di Kabupaten Belu terdapat bulan kering sepanjang 7 bulan (Juni-Desember) dan bulan basah selama 5 bulan (Januari-Mei).

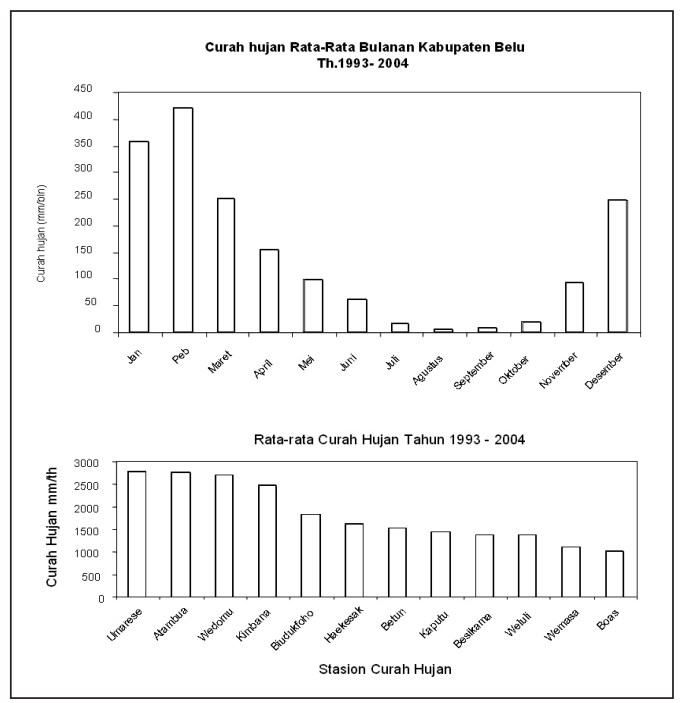

Gambar 1. Pola hujan di Kabupaten Belu berdasarkan data Dinas Pertanian Kabupaten Belu, tahun 1993 - 2004

\section{Tingkat kesesuaian lahan untuk tanaman konservasi daerah tangkapan air}

Berdasarkan hasil survey dan dipadukan dengan persyaratan tumbuh ideal berbagai jenis tanaman ${ }^{3)}$, terdapat beberapa jenis tanaman yang berpotensi untuk di budidayakan sebagai tanaman pangan maupun tanaman penghijauan daerah tangkapan sumber air di Desa Baudaok-Belu, yaitu:

\section{1) Tanaman pangan (jagung, gude)}

Jagung (Zea mays) sebagai tanaman pangan dan gude (Cajanus cajan) sebagai tanaman kacang-kacangan ditanam oleh masyarakat di Desa Baudaok-Belu, Nusa Tenggara Timur pada tanah-tanah jenis mediteranea yang berwarna merah. Meskipun menempati luasan lahan yang relatif sempit, jenis tanah ini lebih subur dibandingkan dengan tanah kapur dan berbatu karang. Jagung dan gude sesuai ditanam pada lahan ini, karena keduanya merupakan jenis tanaman tahan kering. 


\section{2) Buah-buahan (pisang, mangga)}

Pada umumnya pisang (Musa paradisiaca) sesuai bila ditanam di dekat lokasi sumber air. Oleh karena itu di Desa Baudaok, pisang tumbuh subur di dekat sumber mata air Wetihu dan sebaliknya tumbuh 'merana' pada lahan marginal. Untuk pengembangan, perlu dipilih jenis-jenis pisang yang tahan kering.

Berbeda dengan pisang, tampaknya mangga (Mangifera indica) lebih sesuai ditanam di daerah tangkapan air Wetihu. Hal ini terbukti terdapat pohon mangga lokal yang memiliki lingkar batang hingga mencapai $410 \mathrm{~cm}$. Untuk pengembangan perlu dipilih varietas mangga unggul yang diperoleh secara cangkokan atau okulasi.

\section{3) Pakan ternak (lamtoro, turi)}

Lamtoro (Leucaena leucocephala) dan turi (Sesbania grandiflora) sesuai untuk dikembangkan sebagai pakan ternak, meskipun keduanya mempunyai sifat pertumbuhan yang berbeda. Turi lebih cepat pertumbuhannya dibandingkan dengan lamtoro. Oleh karena pertumbuhannya yang cepat maka tanaman turi perlu diregenarasi pada umur 8-10 tahun; dan sebaliknya lamtoro dapat bertahan tumbuh hingga puluhan tahun. Lamtoro sebagai pakan ternak telah lama dikembangkan di daratan Pulau Timor, seperti dianjurkan oleh RajaRaja kepada masyarakat pada zaman dahulu di wilayah Amarasi, Kupang ${ }^{10)}$.

Kendala pengembangan lamtoro dan turi pada usia muda ialah berhadapan dengan ternak, kekeringan dan semak belukar. Apabila tanaman lamtoro dan turi telah mampu melewati usia 1-2 tahun, umumnya tanaman akan bertahan hidup sebagai penghasil pakan ternak.

\section{4) Bahan anyaman dan bangunan (bambu)}

Di Desa Baudaok, bambu (Bambusa sp.) tumbuh dengan baik pada lahan-lahan marginal, yaitu lahan berkapur dan berbatu karang. Tampaknya bambu hanya ditanam untuk memenuhi kebutuhan rumah tangga, baik untuk bahan anyaman maupun bahan bangunan. Pada lahan-lahan yang tidak memungkinkan untuk ditanami tanaman pangan, tampaknya bambu cukup bagus dikembangkan. Selain sebagai tanaman ekonomis, secara ekologis perakaran bambu juga berperanan cukup baik untuk penahan longsoran tanah dan erosi.

\section{5) Kayu bakar dan pohon pelindung (kom, pole, dadap, kapok, gmelina)}

Beberapa jenis tanaman seperti kom (Zizypus mauritiana), pole (Alstonia scholaris), dadap (Erythrina orientalis), kapok (Ceiba pentandra) dan gmelina (Gmelina arborea) dapat disebut sebagai tanaman serbaguna. Selain sebagai penghasil kayu bakar dan pohon pelindung tanaman ini juga sebagai penghasil pakan ternak. Sebagai contoh tanaman kom yang tumbuh dan berkembang dengan cepat pada lahan marginal ini, pada usia muda daunnya digemari ternak. Seiring dengan bertambahnya umur tanaman, ternak kurang suka karena tanaman ini berduri tajam. Tanaman gmelina yang banyak digunakan sebagai tanaman penghijauan, daunnya juga disukai ternak dan batangnya yang sudah besar dapat digunakan sebagai bahan bangunan dengan kayu berkualitas bagus.

\section{6) Bahan arang (kusambi)}

Masyarakat di Pulau Timor mengenal kusambi (Schleichera oleosa) batangnya sebagai bahan pembuatan arang yang berkualitas bagus. Pemanfaatan kusambi untuk bahan pembuataan arang bertahan hingga kini, antara lain untuk penghangat badan saat musim dingin dan untuk perapian bagi Ibu-lbu di desa-desa yang baru melahirkan. 


\section{7) Penghasil minyak pewangi (cendana)}

Di lahan-lahan marginal, di daerah tangkapan air Wetihu, Desa Baudaok-Belu dijumpai anakan-anakan cendana (Santalum album). Tanaman-tanaman cendana tersebut mungkin pernah dibudidayakan, tapi pemeliharaannya terlihat kurang intensif. Cendana sebagai tanaman penghasil minyak parfum dari daratan Pulau Timor, telah dikembangkan sejak sebelum kemerdekaan. Pasang surut pengembangan cendana telah berlangsung sejak paska Kemerdekaan Republik Indonesia, hingga saat ini. Kesesuaian lahan dan iklim untuk pengembangan cendana di daerah tangkapan air Wetihu, BaudaokBelu, NTT sudah tidak perlu diragukan lagi. Permasalahan pengembangan cendana ialah diperlukan partisipasi dan tanggung jawab dari berbagai pihak, karena cendana merupakan tanaman berumur panjang yang dapat diperoleh hasilnya setelah berumur lebih dari 30 tahun.

Jenis-jenis tanaman terpilih seperti tersebut di atas, secara ekologis terbukti sesuai tumbuh dengan kondisi tanah dan iklim setempat yang beriklim kering dan berlahan marginal. Tanaman-tanaman tersebut belum dibudidayakan secara baik dan bahkan sebagian tampak sebagai tanaman liar. Berbagai jenis tanaman berpotensi tersebut perlu dibudidayakan dengan memperhatikan teknis agronomi seperti: (1) pemilihan bibit unggul yang sesuai dengan kondisi tanah dan iklim setempat; (2) pemberian pupuk organik dan anorganik yang cukup; (4) pengaturan jarak tanam yang tepat sehingga mencapai kerapatan populasi per hektar yang optimal; (5) irigasi secara hemat air yang sesuai untuk daerah kering; dan (6) pengendalian hama dan penyakit bila diperlukan. Penghijauan di daerah tangkapan sumber mata air Wetihu, perlu dilakukan pada areal sepanjang $1,5 \mathrm{~km}$ dari sumber mata air menuju ke arah selatan untuk memperbaiki kondisi iklim mikro, konservasi tanah dan sumberdaya air.

\section{KESIMPULAN DAN SARAN}

1. Untuk konservasi daerah tangkapan sumber air Wetihu perlu diprioritaskan jenis-jenis tanaman bernilai ekonomi yang dipilih dari 39 jenis tanaman hasil survey, yakni: tanaman pangan (jagung, gude), buah-buahan (pisang, mangga), pakan ternak (lamtoro, turi), bahan anyaman (bambu), kayu bakar, pohon pelindung (kom, pole, dadap, kapok, gmelina), kusambi (arang), cendana (minyak pengharum). Jenisjenis tersebut terbukti telah mampu beradaptasi dengan iklim kering dan tanah marginal. Untuk pegembangan lebih lanjut diperlukan pemilihan varietas unggul dari jenis-jenis tanaman terpilih tersebut.

2. Tanaman pangan (jagung dan gude) dan tanaman buah (pisang) tampaknya lebih sesuai ditanam pada tanah berjenis mediteranea, bertanah merah yang relatif subur dan lembab. Sedangkan jenis-jenis tanaman lain lain seperti mangga, bambu dan tanaman penghijauan lainnya masih dapat tumbuh baik pada lahan-lahan yang didominasi oleh tanah berbahan induk batu karang dan batu kapur.

\section{DAFTAR PUSTAKA}

1. Arsadi, E.M., H. Bakti, W. Widiyono, E. Kosasih dan Sunardi. 2007. Deliniasi daerah resapan air untuk konservasi mata air di daerah Tasifeto Timur, Kabupaten Belu, NTT. Lap. Akhir Tahun Program Kompetitif, Puslit Geoteknologi-Biro Renkeu dan B3 TTG - LIPI. 43 hal.

2. Bruijnzeel, L.A. 1990. Hydrology of moist tropical forests and effects of conversion: A state of knowledge review. IAHS, UNESCO, Free University, Amsterdam. 224p.

3. Puslit Tanah dan Agroklimat. 1993. Petunjuk Teknis Evaluasi Lahan. 
Puslit Tanah dan Agroklimat, Badan Litbangtan. 113 hal.

4. Drees, E.M. 1951. Distribution, ecology and silvicultural possibilities of the trees and shrubs from the savanna-forest in Eastern Sumbawa and Timor (Lesser Sunda Islands). Communication of the Forest Research Institute, Balai Penyelidikan Kehutanan, Bogor (33):1145.

5. Widiyono, W. 2002. Konservasi 'embung' di Nusa Tenggara Timur melalui analisis tutupan vegetasi dan sumber daya air. Tesis Magister Sains, Jurusan Biologi, F-MIPA, UI. Bag. I. 68 hal. dan Bag. II. 101 hal.

6. Widiyono, W. 2007. Relationship between vegetation and runoff-erosion: consequences on 'embung' water balance in West Timor East Nusa Tenggara Province. Disertasi Bidang Biologi Konservasi, FMIPA, UI. 176p.

7. Widiyono, W. 2008. Konservasi flora, tanah dan sumberdaya air 'embung''embung' di Timor Barat Provinsi Nusa Tenggara Timur (Studi Kasus 'embung' Oemasi Kupang dan 'embung' Leosama Belu). Jurnal Teknologi Lingkungan, Pusat Teknologi Lingkungan, BPPT 7(3): 193-200.
8. LPT. 1990. Term of Reference Tipe-B, Pemanfaatan Tanah dan Survey Lingkungan. Lembaga Penelitian Tanah. 21 hal.

9. Hakim, N., Y. Nyakpa, A.M. Lubis, S.H. Nugroho, M.R. Saul, M.A. Diha, G.B. Hong dan H.H. Bailey. 1986. Dasar-Dasar IImu Tanah. Universitas Lampung. 488.

10. Metzner, J. 1987. Kemajuan berdasarkan masa lampau. Dalam: Metzner, J \& N. Daldjoeni. Ekofarming, Bertani Selaras Alam. Yayasan Obor Indonesia: 263315.

\section{UCAPAN TERIMA KASIH}

Penulis menyampaikan ucapan terima kasih yang setinggi-tingginya kepada Dr. Edy M. Arsadi atas kesempatan yang diberikan untuk ikut serta sebagai anggota team peneliti dalam kegiatan yang berjudul: 'Deliniasi daerah resapan air untuk konservasi mata air di daerah Tasifeto Timur, Kabupaten Belu, NTT'. Penelitian ini merupakan Program Kompetitif, Puslit Geoteknologi - Biro Perencanaan dan Keuangan dan Balai Besar Pengembangan TTG - LIPI, tahun 2007. 
Lampiran 1. Jenis dan Manfaat Tanaman Di Daerah Tangkapan Air Desa Baudaok, Kec. Tasifeto Timur, Kabupaten. Belu, tahun 2007

\begin{tabular}{|c|c|c|c|}
\hline No. & Nama Lokal & Nama Latin & Manfaat \\
\hline 1 & Akasia & Acacia auriculiformis & Kayu bakar, bahan bangunan \\
\hline 2 & Asam & Tamarindus indica & $\begin{array}{l}\text { Buah, daun untuk pakan ternak, kayu bakar, } \\
\text { bangunan }\end{array}$ \\
\hline 3 & Bambu andong & Bambusa sp. & Bahan bangunan, rumah tangga \\
\hline 4 & Bambu hiris & Bambusa sp. & Bahan bangunan, rumah tangga \\
\hline 5 & Beringin & Ficus sp. & Pelindung \\
\hline 6 & Buah nona & Annona squamosa & Buah \\
\hline 7 & Bunga putih & Chromolaena odorata & Tumbuhan liar \\
\hline 8 & Cendana & Santalum album & Minyak, kayunya \\
\hline 9 & Dadap & Erythrina orientalis & Pohon pelindung, kayu bakar \\
\hline 10 & Gmelina & Gmelina arborea & Pohon pelindung, pakan ternak, kayu bakar \\
\hline 11 & Gude & Cajanus cajan & Tanaman pangan \\
\hline 12 & Jagung & Zea mays & Tanaman pangan \\
\hline 13 & Jambu biji & Psidium guajava & Buahnya \\
\hline 14 & Jambu mente & Anacardium occidentale & Buahnya \\
\hline 15 & Jarak rambutan & Ricinus communis & Bijinya \\
\hline 16 & Jati & Tectona grandis & Bahan kayu bangunan \\
\hline 17 & Johar & Cassia siamea & Bahan kayu bangunan, kayu bakar \\
\hline 18 & Kapok & Ceiba pentandra & Pohon pelindung, kayu bakar \\
\hline 19 & Kedondong hutan & Lanea grandis & Pagar, kayu bakar \\
\hline 20 & Kelapa & Cocos nucifera & Buahnya, dan bahan kayu bangunan \\
\hline 21 & Kemiri & Aleurites molluccana & Buahnya, dan bahan kayu bangunan \\
\hline 22 & Kom & Zizypus timorensis & Pohon pelindung, kayu bakar \\
\hline 23 & Kukbai & Cordia subcordata & Pohon pelindung, kayu bakar \\
\hline 24 & Kusambi & Schleichera oleosa & Pohon pelindung, kayu baker, arang \\
\hline 25 & Lamtoro & Leucaena leucocephala & Pakan ternak, kayu bakar \\
\hline 26 & Litsusu (laialar) & Wrightia calysina & Pohon pelindung, tanaman obat \\
\hline 27 & Mangga & Mangifera indica & Buahnya \\
\hline 28 & Mindi & Azadirachta sp. & Pohon pelindung, kayu bakar \\
\hline 29 & Nangka & Artocarpus integra & Buahnya \\
\hline 30 & Nikis & Cassia fistula & Pohon pelindung, kayu bakar \\
\hline 31 & Oné-oné & Lantana camara & Tumbuhan liar, semak belukar \\
\hline 32 & Pakis & Cycas sp. & Tumbuhan liar, tanaman hias \\
\hline 33 & Pepaya & Carica papaya & Buahnya \\
\hline 34 & Pisang & Musa paradiciaca & Buahnya \\
\hline 35 & Pole & Alstonia scholaris & Pohon pelindung, kayu bakar \\
\hline 36 & Sirih & Piper batle & Daunnya \\
\hline 37 & Sirsak & Anona muricata & Buahnya \\
\hline 38 & Sufmolok & Stenolobium stan & Tumbuhan liar, perdu, kayu bakar \\
\hline 39 & Turi & Sesbania grandiflora & Pakan ternak, kayu bakar \\
\hline
\end{tabular}

